\title{
SUSCEPTIBILITY EVALUATION AND MAPPING OF CHINA'S LANDSLIDE DISASTER BASED ON MULTI-TEMPORAL GROUND AND REMOTE SENSING SATELLITE DATA
}

\author{
Chun $\mathrm{Liu}^{\mathrm{a}, \mathrm{b}}$, Weiyue $\mathrm{Li}^{\mathrm{a}, \mathrm{b} *}$, Ping Lu $\mathrm{L}^{\mathrm{a}}$, Kai Sang ${ }^{\mathrm{b}}$, Yang Hong ${ }^{\mathrm{a}}$ and Rongxing $\mathrm{Li}^{\mathrm{a}}$ \\ ${ }^{\mathrm{a} C e n t e r ~ f o r ~ S p a t i a l ~ I n f o r m a t i o n ~ S c i e n c e ~ a n d ~ S u s t a i n a b l e ~ D e v e l o p m e n t, ~ T o n g j i ~ U n i v e r s i t y, ~ C h i n a ~}$ \\ ${ }^{\mathrm{b}}$ Department of Surveying and Geo-Informatics, Tongji University, China
}

\section{Commission VIII, WG VIII/1}

KEY WORDS: landslide, empirical model, ANN learning, susceptibility, hazard mapping

\begin{abstract}
:
Under the circumstances of global climate change, nowadays landslide occurs in China more frequently than ever before. The landslide hazard and risk assessment remains an international focus on disaster prevention and mitigation. It is also an important approach for compiling and quantitatively characterizing landslide damages. By integrating empirical models for landslide disasters, and through multi-temporal ground data and remote sensing data, this paper will perform a landslide susceptibility assessment throughout China. A landslide susceptibility (LS) map will then be produced, which can be used for disaster evaluation, and provide basis for analyzing China's major landslide-affected regions. Firstly, based on previous research of landslide susceptibility assessment, this paper collects and analyzes the historical landslide event data (location, quantity and distribution) of past sixty years in China as a reference for late-stage studies. Secondly, this paper will make use of regional GIS data of the whole country provided by the National Geomatics Centre and China Meteorological Administration, including regional precipitation data, and satellite remote sensing data such as from TRMM and MODIS. By referring to historical landslide data of past sixty years, it is possible to develop models for assessing LS, including producing empirical models for prediction, and discovering both static and dynamic key factors, such as topography and landforms (elevation, curvature and slope), geologic conditions (lithology of the strata), soil type, vegetation cover, hydrological conditions (flow distribution). In addition, by analyzing historical data and combining empirical models, it is possible to synthesize a regional statistical model and perform a LS assessment. Finally, based on the $1 \mathrm{~km} \times 1 \mathrm{~km}$ grid, the LS map is then produced by ANN learning and multiplying the weighted factor layers. The validation is performed with reference to the frequency and distribution of historical data.

This research reveals the spatiotemporal distribution of landslide disasters in China. The study develops a complete algorithm of data collecting, processing, modelling and synthesizing, which fulfils the assessment of landslide susceptibility, and provides theoretical basis for prediction and forecast of landslide disasters throughout China.
\end{abstract}

\section{INTRODUCTION}

Natural disasters are abnormal and inevitable phenomena, from the nature on which human beings depend to live. It did harm to the human society, mainly including earthquake, volcano, landslide, debris flow, typhoon, flood, soil erosion, desertification, water pollution, and so on. These disasters are complicated and closely connected with environmental degradation and human life (Henderson, 2004). The casualties and property losses caused by landslide are often listed first in the natural disaster damage. Landslide is defined as the

\footnotetext{
${ }^{*}$ Weiyue Li(1983-), male, PhD candidate, main research interests-laser scanning data processing and application.
} 
phenomenon that a large number of mountain materials suddenly downward slides along a sliding surface of the interior in the gravity by a variety of external factors, for instance, earthquake, volcano, river erosion, snow melt, rainfall and human activities (Kirschbaum et al, 2010). Especially, the destructive force of other secondary disasters induced by large landslide far exceeds its direct damage. In recent years, mudslides which were affected by global climate change occurred frequently. More than 90,000 landslide hidden dangers are located in 70 cities and counties of several southern and north-western provinces in China, and tens of millions of people live under the threat of landslide throughout the year. Landslide caused thousands of deaths and tens of billions of property loss (Zhou et al, 2005). Therefore, landslide monitoring, assessment and prediction are advanced subjects of international landslide disaster research and environmental engineering geology field nowadays.

Many causes of landslide occurrence mainly include terrain, geology, geomorphy, weather conditions, land cover, and so on (Parry, 2011). Obtaining the relationships between these above factors and landslide occurrence is very important for the quantitative evaluation of landslide susceptibility (LS) and hazards. LS assessment is the quantitative or qualitative evaluation for the existing or potential type, volume, distribution of some area's landslide, and LS mapping would conduce to us the space distribution of one regional slope instability probability (Mathew et al, 2008). It is the first and most step of landslide risk assessment, in order to make effective measures of landslide mitigation. Reliable susceptibility assessment depends on the quality and range of the available data and the selection of method for modelling to identify landslide, analyze landslide formation conditions and characteristics, show landslide detailed geometric description. LS assessment typically excludes the prediction of occurrence time, is an important feature of susceptibility evaluation (Ercanoglu, 2008).

Based on historical data and practical experience, empirical landslide susceptibility assessments adopt the statistical approach and pattern recognition methods to construct empirical models. Meanwhile, empirical weights of landslide factors can be obtained by the initial analysis; and spatial associations between spatial factors and landslides will be showed in a GIS (Geographic Information System). Artificial neural network (ANN) can analyze complex data at different scales such as continuous, indexical and binary data (Chauhan et al, 2010). Based on learning from data with known characteristics to obtain the weights of factors, ANN is used to recognize the unseen data (Pradhan, 2011). In this paper, we used the ANN black box by capturing the connection weights among various inputs, with multi-temporal ground and remote sensing satellite data for susceptibility evaluation and mapping of China's landslide disaster.

\section{STUDY AREA AND DATA}

China lies in the east of the Asia-Europe Continent, on the western shore of the Pacific Ocean, and covers about 9.6 million $\mathrm{km} 2$ land area (between latitudes $3.85^{\circ} \mathrm{N}$ and $53.56^{\circ} \mathrm{N}$, between longitudes $73.55^{\circ} \mathrm{E}$ and $135.08^{\circ} \mathrm{E}$ ). The terrain of China is high in east but low in west. Mountain, plateau and hills cover about $67 \%$ of the land area; basin and plain cover about 33\%. China is one of the countries which are most vulnerable to landslide disaster. Some studies indicated that landslide disaster mainly happened in a steep slope such as the river and stream coast of bank slope zone, and the gorges with high level difference; in geological tectonic belt (fractures or structural zones); in the soft rock-soil (loose covering layer, loess, mudstone, shale, coal beds); in some areas with heavy rainfall (He et al, 2008).

The reports of the landslide events for nearly 60 years were obtained mainly from online news reports, yearbooks, and hazard database, including: China Geological Environmental Information Network (CGEIN, http://www.cigem.gov.cn/); China Risk Network (CRN, http://www.irisknet.cn/); Geostress and Geological Disaster Querying Database (GGDQD, http://www.geomech.ac.cn/geo0503/); China Statistical Yearbook (1950-2011); China major landslide reports (from newspaper and media). Since the 1980s, numbers of reports started to increase, concerned with the government's attention. To be emphasized, numbers of landslide reports of the south and southwest are more than that of other regions.

Many causes of landslide occurrence previous mentioned can be divided into two main categories (Wu and Sidle, 1995):

(1) Internal factors: those that have decision effects on landslide, including geology, geomorphology, slope gradient, slope aspect, elevation, soil property, vegetation cover, flow distribution, fracture, and so on.

(2) External factors: they will trigger landslide suddenly, such as earthquake, rainfall. 
Obviously, the variation of external factors is a short process, and usually unpredictable; the distribution of internal factors act on LS. The relevant data were provided by the National Geomatics Centre, and network: (https://modaps.nascom.nasa.gov:8499/,http://srtm.csi.cgiar.org /SELECTION/inputCoord.asp)(Table1).

Table 1. Data sources and specific use.

\begin{tabular}{|c|c|c|c|c|}
\hline Data types & \multicolumn{3}{|c|}{ Description } & Specific use \\
\cline { 2 - 5 } & Satellite/sensor & Spatial resolution & Year of acquisition & Vegetation cover \\
\hline Remote sensing data & Terra, Aqua/MODIS & $250 \mathrm{~m}$ & $2003-2011$ & $\begin{array}{c}\text { Slope gradient, } \\
\text { aspect, elevation }\end{array}$ \\
\hline $\begin{array}{c}\text { DEM(Digital Elevation } \\
\text { Model) }\end{array}$ & & $90 \mathrm{~m}$ & 2000 & Lithology \\
\hline Geological maps & & Scale: $1: 500,000$ & 2000 & Soil type \\
\hline Soil type maps & & Scale: $1: 3,000,000$ & 2000 & Convexity \\
\hline Geomorphologic maps & & Scale: $1: 3,000,000$ & 2000 & Flow distribution \\
\hline River distribution maps & & Scale: $1: 3,000,000$ & 2000 & Fracture \\
\hline $\begin{array}{c}\text { Seismic zone distribution of } \\
\text { China }\end{array}$ & & & 2008 & \\
\hline
\end{tabular}

\section{LANDSLIDE FACTORS IDENTIFICATION}

The quantification of different factors is to select the landslide region per unit area. It can be seen the parameters to describe the relationship between factors and landslide (Kumar et al, 2010). Because the historical data collected mainly reflected the numbers of landslide occurrence, relative probabilities of different distribution intervals were qualitatively analyzed. RPmn is the relative probability that factor $m$ lies within the range $\mathrm{n}$ with the following formula (1):

$$
R P_{m n}=\frac{P_{m n}}{P_{m}}
$$

Synthesizing the above analysis, the factors associated with LS were categorized according to the different levels (Table 2). According to the summary from CDSTM, the formation conditions of landslide in China which mainly contained:
Jurassic, Mudstone of Cretaceous, Shale, Argillaceous Sandstone, Siltstone, Coal Beds, Sandy Slate, Phyllite; the types of convexity include: concave, flat, protrude; with the increase of slope gradient, the component force of gravity in the slope direction, and landslide would have higher risks (Dai et al, 2002); slope aspect is mainly divided into eight directions; the relationship exists between elevation and landslide, such as in high mountains, which were comprised of weathered and tough rocks, that is less likely for landslide ; the higher the vegetation coverage is, the smaller the landslide possibility; meanwhile, landslide is bound up with the distribution of flow and fracture (Montgomery et al, 2002).

CDSTM: (China Digital Science and Technology Museum, http://amuseum.cdstm.cn/moundisaster/ page/knowledgec.jsp?pid=3100502)

Table 2. Evaluation factors and classifications

\begin{tabular}{|c|c|c|c|c|c|c|c|c|}
\hline \multirow[t]{2}{*}{ Factors } & \multicolumn{8}{|c|}{ Classification } \\
\hline & 1 & 2 & 3 & 4 & 5 & 6 & 7 & 8 \\
\hline Lithology & $\mathrm{J}$ & $\mathrm{M}$ & $\mathrm{S}$ & A & $\mathrm{Si}$ & Co & Sa & $\mathrm{P}$ \\
\hline Convexity & Concave & Flat & Protrude & & & & & \\
\hline Gradient & $0 \sim 10^{\circ}$ & $10^{\circ} \sim 20^{\circ}$ & $20^{\circ} \sim 30^{\circ}$ & $30^{\circ} \sim 40^{\circ}$ & $40^{\circ} \sim 50^{\circ}$ & $>50^{\circ}$ & & \\
\hline Aspect & East & Southeast & South & Southwest & West & Northwest & North & Northeast \\
\hline Elevation(km) & $<0.5$ & $0.5 \sim 1.0$ & $1 \sim 1.5$ & $1.5 \sim 2.0$ & $2.0 \sim 2.5$ & $2.5 \sim 3.0$ & $>3.0$ & \\
\hline Soil property & $\mathrm{R}$ & $\mathrm{Y}$ & YB & $\mathrm{B}$ & $\mathrm{Ci}$ & DB & $\mathrm{BC}$ & $\mathrm{F}$ \\
\hline $\begin{array}{c}\text { Vegetation } \\
\text { Coverage (\%) }\end{array}$ & $<20$ & $20 \sim 40$ & $40 \sim 60$ & $60 \sim 90$ & $>90$ & & & \\
\hline Flow $(\mathrm{km})$ & $<100$ & $100 \sim 200$ & $200 \sim 300$ & $300 \sim 400$ & $400 \sim 500$ & $>500$ & & \\
\hline Fracture $(\mathrm{km})$ & $<0.5$ & $0.5 \sim 1.0$ & $1.0 \sim 1.5$ & $1.5 \sim 2.0$ & $2.0 \sim 2.5$ & $2.5 \sim 3.0$ & $>3.0$ & \\
\hline
\end{tabular}

(Notes: J, M, S, A, Si, C, Sa, P represent the eight lithology of causing landslide: Jurassic, Mudstone of Cretaceous, Shale, Argillaceous Sandstone, Siltstone, 


\section{LS ASSESSMENT AND ANALYSIS BASED ON ANN}

\subsection{ANN concepts}

ANNs are generic non-linear functions that have been broadly used to solve many problems like confirming weight values and classification, with processing unit, network topology, and training rules. Multi-Layer Perception (MLP) as a frequently used ANN, includes input, output, and one or more hidden layers between in-out layers. Meanwhile, the number of neurons from the input to output layers is typically fixed by the model designed. By trial and error, the neurons and the number of hidden layers can be determined (Gong, 1996). There are three steps involved in ANN data processing, including: the training, the weights confirmation, the classification. Training data from input neurons are processed through hidden nodes to obtain output values. If the input that a single neuron $\mathrm{j}$ with the only one hidden layer, may be expressed as:

$$
\text { net }_{j}=\sum_{i=1}^{t} w_{i j} p_{i}
$$

Where $w_{i j}$ represents the weights between the node $i$ of input layer and the node $j$ of hidden layer; $p_{i}$ is the input data; $t$ represents the number of input layers. The relative probabilities of factors into LS values may also be regarded as the problem of judging weights. Input layers include the above 9 factors:
Lithology, Convexity, Gradient, Aspect, Elevation, Soil property, Vegetation cover, Flow, Fracture; the ANN output may be considered as the measurements of the occurrence of landslide (Figure 1).

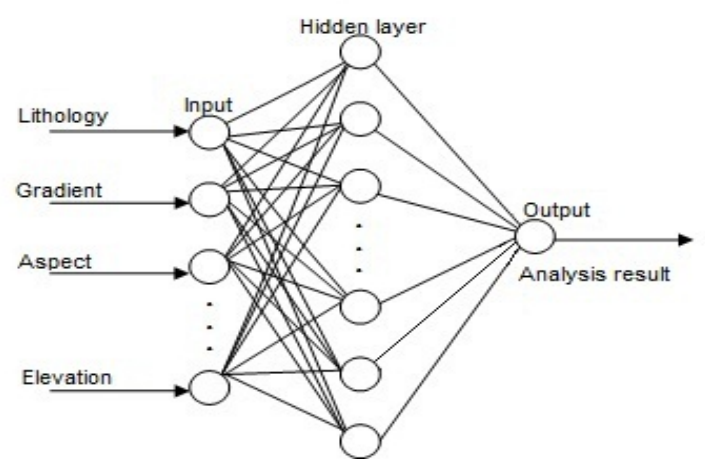

Figure 1. ANN structure chart of LS analysis

\subsection{Factors acquisition of the samples}

With the previous 1,200 records, and the equation (1), occurrence frequencies of different input factors (quantitative values) had been obtained (Table 3).

Table 3 Occurrence frequencies of different input factors

\begin{tabular}{|c|c|c|c|c|c|c|c|c|}
\hline \multirow{2}{*}{$\begin{array}{c}\text { Frequencies } \\
\text { of factors }\end{array}$} & \multicolumn{9}{|c|}{ Classification } \\
\cline { 2 - 9 } & 1 & 2 & 3 & 4 & 5 & 6 & 7 & 8 \\
\hline Lithology & 0.12 & 0.09 & 0.17 & 0.24 & 0.15 & 0.11 & 0.04 & 0.08 \\
\hline Convexity & 0.58 & 0.26 & 0.16 & 0 & 0 & 0 & 0 & 0 \\
\hline Gradient & 0 & 0.03 & 0.16 & 0.29 & 0.27 & 0.25 & 0 & 0 \\
\hline Aspect & 0.14 & 0.16 & 0.18 & 0.17 & 0.15 & 0.09 & 0.09 & 0.08 \\
\hline Elevation & 0.01 & 0.14 & 0.17 & 0.22 & 0.19 & 0.19 & 0.08 & 0 \\
\hline $\begin{array}{c}\text { Soil } \\
\text { property }\end{array}$ & 0.38 & 0.36 & 0.15 & 0.02 & 0.05 & 0.02 & 0 & 0.02 \\
\hline $\begin{array}{c}\text { Vegetation } \\
\text { Coverage }\end{array}$ & 0.34 & 0.25 & 0.23 & 0.11 & 0.07 & 0 & 0 & 0 \\
\hline Flow & 0.30 & 0.25 & 0.24 & 0.12 & 0.06 & 0 & 0 & 0 \\
\hline Fracture & 0.36 & 0.20 & 0.15 & 0.13 & 0.11 & 0.05 & 0 & 0 \\
\hline
\end{tabular}

The occurrence frequencies reflect the number of landslide reports, and output data were set as the summary of different factor frequencies (3).

$$
Z=X_{1}+X_{2}+\cdots+X_{n}
$$

Where $\mathrm{Xn}$ is quantitative value from every factor; $\mathrm{n}$ is the number of factors. $\mathrm{Z}$ for the ANN trainings would be normalized between 0 and 1 .

\subsection{LS mapping and analysis}

According to the above methods mentioned, the qualitative 
values were selected from 1,200 landslide records, and the summary of different frequencies every sample were considered as the output data. The number of neurons of hidden layer is more than twice the input data. The structure of Neural network is "9-18-1". The BP learning algorithm, with network training error of 10-6, and 500 times of training (Figure 2), was implemented to train various ANN architectures.

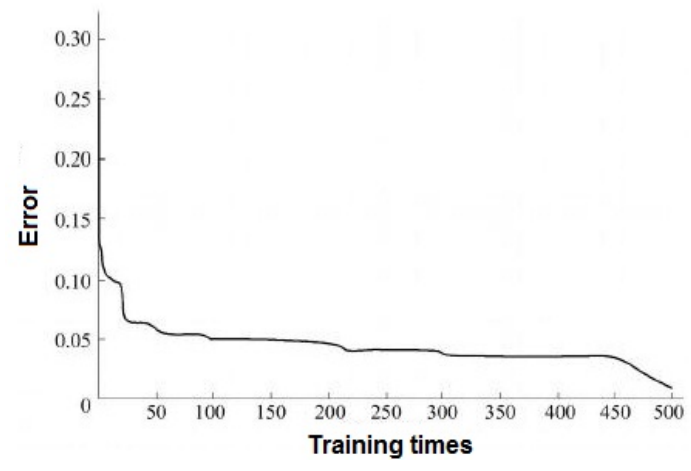

Figure 2. Error and training times of ANN

Some landslide test data were from worldwide authoritative website (United States Geological Survey (USGS), http://landslides.usgs.gov/recent; EM-DAT International Disaster Database, http://www.em-dat.net/; International Consortium on Landslides Website (ICL), http://iclhq.org/). Gathering 100 landslide test data, the accuracy of the network is about $82.31 \%$. The output data were considered to express the LS index values of pixels. The higher the value of LS, the more susceptible is that pixel to the occurrence frequencies of landslide. Based on the $1 \mathrm{~km} \times 1 \mathrm{~km}$ grid, the LS map of China is then produced by ANN learning and multiplying the weighted factor layers (Figure 3).

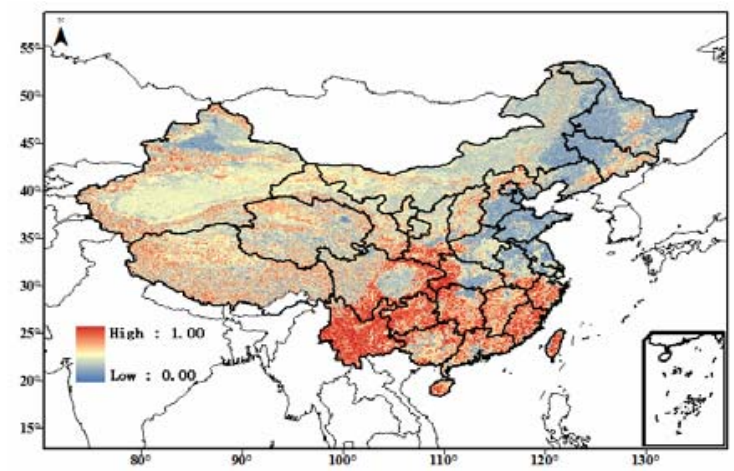

Figure 3. LS map of China based on multi-factors

From the figure can clearly see that the southwest of China has higher susceptibility index than other areas, which also could be consistent with landslide reports from news. Meanwhile, the rainfall data from TRMM satellite can be used to predict the landslide area by overlaying the LS map.

\section{CONCLUSIONS}

The most prominent features of landslide include information diversity, fuzziness, uncertainty and randomness, which bring great difficult for information processing. The processing ability of traditional ways and methods is limited, and may cause a lot of useful information losses, result in the degree of reliability reducing. With the strong nonlinear mapping capability, can simulate the possibility of the landslide and the relationship of complex factors (Chacón et al, 2006).

A landslide susceptibility model has been developed for the whole country applying a scoring system with a set of relevant factors based on BP ANN, merging nonlinear elements by qualitative and quantitative indices. The result has been tested by the data of worldwide authoritative website, and the accuracy of the network is about $82.31 \%$ to meet landslide study requirements. The high susceptibility parts mainly in the southwest of China, characterized by the presence of landslide-prone sedimentary rocks, high seismicity, frequent severe earthquake and rainfall events and significant human activities in this area.

The landslide susceptibility evaluation and mapping of China generated in this study constitutes a preliminary step for further more detailed susceptibility and hazard research, as well as a useful method for risk assessment, and provides theoretical basis for prediction and forecast of landslide disasters throughout China.

\section{Acknowledgements}

The work described in this paper was supported by National Basic Research Program of China (2012CB957702) and Innovation Program of Shanghai Municipal Education Commission(Project ID:10ZZ25), and also supported by the Centre of Spatial Information Science and Sustainable Development, Tongji University.

\section{References}

Henderson L J. Emergency and disaster: pervasive risk and pubic bureaucracy in developing nations [J]. Pubic Organization Review: A Global Journal, 2004, 4: 103-119.

Kirschbaum D B, Adler R, Hong Y, et al. A global landslide catalog for hazard applications: method, results, and limitations [J]. Nature Hazards, 2010, 52: 561-575. 
Zhou, P., Zhou, B., Guo, J., et al. 2005. A demonstrative GPS-aided automatic landslide monitoring system in Sichuan Province. Journal of Global Positioning Systems. 4(1-2), pp.184-191.

Parry S. Chapter Fifteen- The application of geomorphological mapping in the assessment of landslide hazard in Hong Kong. Developments in Earth Surface Processes, 2011, 15: 413-441.

Mathew J, Jha V K, Rawat G S. Landslide susceptibility zonation mapping and its validation in part of Garhwal Lesser Himalaya, India, using binary logistic regression analysis and receiver operating characteristic curve method. Landslides. 2008, 6(1): 17-26.

Ercanoglu M. An overview on the landslide susceptibility assessment techniques. 1st WSEAS International Conference on ENVIRONMENTAL and GEOLOGICAL SCINENCE and ENGINEERING. 2008, Valletta, Malta.

Chauhan S, Sharma M, Arora M K, et al. Landslide susceptibility zonation through ratings derived from artificial neural network. International Journal of Applied Earth Observation and Geoinformation. 2010, 12(5): 340-350.

Pradhan, B. 2011. Use of GIS-based fuzzy logic relations and its cross application to produce landslide susceptibility maps in three test areas in Malaysia. Environmental Earth Sciences, 63, pp.329-349.

He, K. Q., Li, X. R., Yan, X. Q. 2008. The landslides in the three gorges reservoir region, China and the effects of water storage and rain on their stability. Environmental Geology. 55(1), pp.55-63.

Wu. W, Sidle, R. C. 1995. A distributed slope stability model for steep forested watersheds. Water Resources Research, 31(8), pp.2097-2110.

Kumar K, Devrani R, Mathur S. Landslide hazard potential analysis using GIS, Patalganga Valley, Garhwal, western Himalayan region of India. European Journal of Scientific Research. 2010, 45(3): 346-366.

Dai, F. C., Lee, F. C., Ngai,Y. Y. 2002. Landslide risk assessment and management: an overview. Engineering Geology.64(1), pp.65-87.

Montgomery D R, Dietrich W E, Heffner J T. Piezometric response in shallow bedrock at CB1: implications for runoff generation and landsliding. Water Resources Research. 2002, 38(12): 1274-1292.

Gong, P. 1996. Integrated analysis of spatial data for multiple sources: using evidential reasoning and artificial neural network techniques for geological mapping. Photogrammetric Engineering \& Remote Sensing. 62, pp.513-523.

Chacón, J., Irigaray, C., Fernández, T. 2006. Engineering geology maps: landslides and geographical information systems. Bulletin of Engineering Geology and the Environment. 65(4), pp.341-411. 